\title{
Hyperglycemia: the metabolic syndrome component that aggravates erectile dysfunction in Mexican patients
}

\section{Hiperglucemia: el componente del síndrome metabólico que agrava la disfunción eréctil en pacientes mexicanos}

\author{
iDAlan Espinosa-Marrón, ${ }^{1}$ iDChristian Aníbal Quiñones-Capistrán, ${ }^{1}$ iDAquiles Rubio-Blancas, ${ }^{1}$ \\ iDMaría del Pilar Milke-García, ${ }^{1}$ iD Ricardo Alonso Castillejos-Molina. ${ }^{\text {* }}$
}

Keywords:

Erectile dysfunction, Metabolic syndrome,

Risk factors, Hyperglycemia.

Correpondencia:

* Ricardo Alonso

Castillejos-Molina.

Dirección: Vasco de Quiroga 15, Sección XVI, Tlalpan, 14000. Ciudad de

México, México. Correo electrónico: rcastillejos@

hotmail.com Teléfono:

(00) (52) 5554870900

ext. 2260

\section{Abstract}

Objectives: To analyze the relationship between erectile dysfunction and metabolic syndrome in a group of Mexican patients, study the influence of other morbidity factors on erectile dysfunction, and define the specific metabolic syndrome components most associated with erectile dysfunction severity.

Materials and methods: A descriptive, cross-sectional study was conducted on a group of 86 adult Mexican patients previously diagnosed with erectile dysfunction. Participants were classified as presenting with or not presenting with metabolic syndrome. Anthropometric, biochemical, and clinical parameters were determined and erectile dysfunction severity, alcohol or tobacco consumption, and depressive behavior were identified through validated questionnaires. The results were compared between the two groups.

Results: The anthropometric measures, laboratory values, and clinical characteristics were significantly different between the two groups. More patients with severe and moderate erectile dysfunction were identified in the group with metabolic syndrome. Of the metabolic syndrome components, glycated hemoglobin $>5.7 \%$ and fasting glucose $>110 \mathrm{mg} / \mathrm{dl}$ were significantly associated with the development of erectile dysfunction.

Limitations: The size of our study sample was a limitation, as was the observational and cross-sectional study design.

Originality: Our study results suggest that metabolic syndrome contributed to the progression of erectile dysfunction in the Mexican sample analyzed, with hyperglycemia being the most strongly associated factor.

Conclusions: Metabolic syndrome components were shown to aggravate erectile dysfunction, particularly the lack of glycemic control. The inclusion of fasting glucose and glycated hemoglobin as complementary biochemical screening in patients with erectile dysfunction should be assessed.

Citación: Espinosa-Marrón A, Quiñones-Capistrán CA, Rubio-Blancas A, Milke-García MP, Castillejos-Molina RA. Hyperglycemia: the metabolic syndrome component that aggravates erectile dysfunction in Mexican patients. Rev Mex Urol. 2019;79(6):pp 1-12.

${ }^{1}$ Instituto Nacional de Ciencias Médicas y Nutrición “Salvador Zubirán”, Secretaría de Salud, Ciudad de México, México.

Recepción: 26 noviembre de 2019 Aceptación: 30 de diciembre de 2019

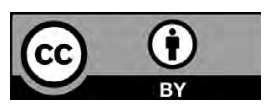




\section{Hiperglucemia: el componente del síndrome metabólico que agrava la disfunción... Espinosa -Marrón A., et al.}

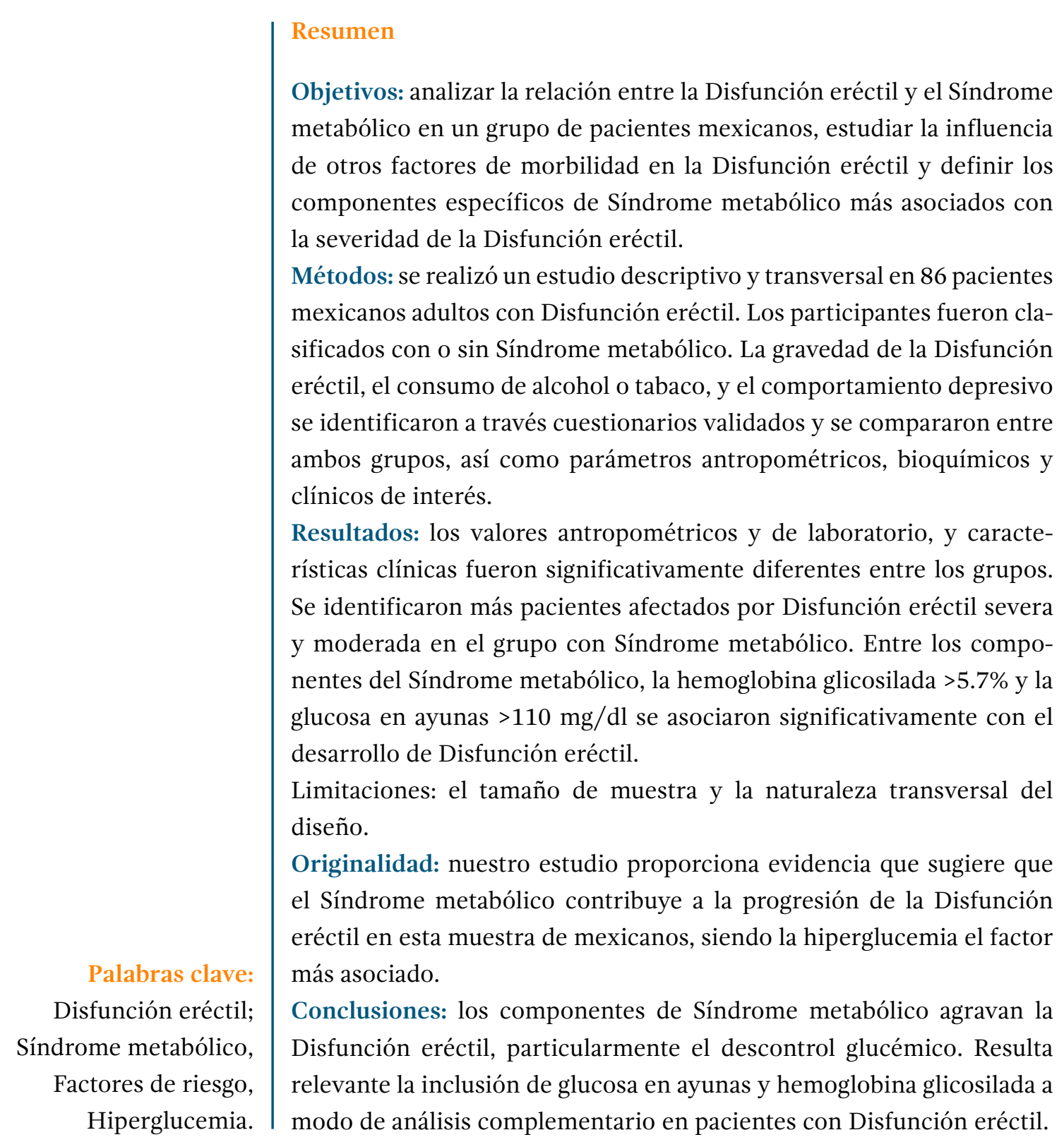

\section{Introduction}

Metabolic syndrome refers to a set of multifactorial alterations that increase the risk of developing type 2 diabetes mellitus and cardiovascular disease. ${ }^{(1)}$ Different international institutions have proposed diagnostic criteria.
However, the Adult Panel Treatment III incorporated standardized key concepts, thus those criteria are some of the most frequently used in clinical practice for the diagnosis of metabolic syndrome: (i) blood pressure $(\geq 130 / \geq 85$ 
mmHg), (ii) high-density lipoprotein cholesterol (HDL-C $<40 \mathrm{mg} / \mathrm{dL}$ ), (iii) triglycerides ( $\geq 150 \mathrm{mg} / \mathrm{dL}_{\text {) }}$, (iv) waist circumference (WC $>102 \mathrm{~cm}$ ), and (v) fasting glucose ( $\geq 100 \mathrm{mg} /$ $\mathrm{d} / \mathrm{L}$ ). A positive diagnosis is made when three of those five criteria are present. ${ }^{(2)}$ Metabolic syndrome affects up to $30 \%$ of the population in developed countries and its incidence is on the rise. ${ }^{(3)}$ Prevalence in Mexican men varies from 45.3 to $46.4 \% .^{(4,5)}$

Erectile dysfunction refers to the inability to achieve an erection as part of the multifaceted process of male sexual function. Erectile dysfunction is common among men over 50 years of age. ${ }^{(6)}$ Etiological factors include anatomic, vascular, psychological, neurological, and hormonal disorders. ${ }^{(7)} \mathrm{A}$ total of $51.1 \%$ of Mexican men between 40 and 60 years of age are estimated to have changes in erectile function, 59.8\% of whom are diagnosed with overt erectile dysfunction.6 Furthermore, projections have established that the worldwide population presenting with erectile dysfunction will reach 322 million cases by 2025 . $^{(6)}$

The global prevalence of metabolic syndrome in subjects with erectile dysfunction varies between 29.4 and $79 \%$. $^{(8,9)}$ Several studies have found a close association between the two alterations, ${ }^{(3,8,9)}$ given that mechanisms underlying metabolic syndrome compromise the blood flow to the penis in numerous ways. (7) Specifically, an association between erectile dysfunction and hypertension, ${ }^{(10)}$ type 2 diabetes mellitus, ${ }^{(11)}$ cardiovascular disease and dyslipidemia, ${ }^{(12)}$ and obesity and central adiposity has been described. ${ }^{(13)}$ Recent studies performed on a Mexican population have confirmed that the lack of glycemic control in patients with type 2 diabetes mellitus increases the risk of developing erectile dysfunction. ${ }^{(14)}$

Despite the publication of many studies on the relation of the different components of metabolic syndrome to erectile dysfunction, ${ }^{(3,5,15)}$ the topic has not been thoroughly explored in the Mexican population, nor have the specific components of that syndrome been emphasized or identified as the most commonly associated with erectile dysfunction, its progression, and its severity. Our main objective was to analyze the relationship between metabolic syndrome and erectile dysfunction in a group of Mexican patients. Our secondary aims were to study the influence of other morbidity factors on erectile dysfunction and to define the specific metabolic syndrome components most strongly associated with erectile dysfunction severity and progression.

\section{Materials and Methods \\ Design}

An observational, cross-sectional study was conducted on a group of men (30-60 years of age) that were regularly seen at the Urology outpatient service of the Instituto Nacional de Ciencias Médicas y Nutrición "Salvador Zubirán” between 2014 and 2017. The study was approved by the local Ethics Committee (approval number URO-844-13/13-1), according to national and international regulations for human studies and the 1964 Declaration of Helsinki. Individual written statements of informed consent were obtained from all participants included in the study. 


\section{Hiperglucemia: el componente del síndrome metabólico que agrava la disfunción... Espinosa -Marrón A., et al.}

\section{Participants and settings}

Patients were recruited through a printed announcement at the Urology Department. A total of 126 patients previously diagnosed with erectile dysfunction were identified. Inclusion criteria were individuals with or without type 2 diabetes mellitus ( $<10$ years of evolution), controlled dyslipidemia (triglycerides $\leq 300$ $\mathrm{mg} / \mathrm{dL}$, low-density lipoprotein cholesterol $\leq 200 \mathrm{mg} / \mathrm{dL}$, with or without pharmacological treatment), controlled systemic blood pressure ( $<140 / 90$ mmHg only using one antihypertensive drug) and overweight or obesity (body mass index $\geq 25$ or $30 \mathrm{~kg} / \mathrm{m} 2$, respectively). Exclusion criteria were uncontrolled glycemia (glycated hemoglobin $\geq 8 \%$ ), uncontrolled hypertension (using two or more antihypertensive drugs, without reaching treatment goals), pharmacologic treatment for erectile dysfunction, prostate surgery, neuropathy, major depressive disorder (Beck Depression Inventory score $>25$ ), hormonal replacement therapy, pelvic radiotherapy, chronic kidney disease (glomerular filtration rate $<60 \mathrm{ml} /$ min, according to the CKD-EPI formula), uncontrolled dyslipidemia (triglycerides $\geq 300 \mathrm{mg} /$ $\mathrm{dL}$ or low-density lipoprotein cholesterol $\geq 200$ $\mathrm{mg} / \mathrm{dL}$ ), possible or diagnosed hypogonadism, hypothyroidism, liver cirrhosis, alcoholism (Alcohol Use Disorder Identification Test score $>8$ ), acute myocardial infarction within the last 6 months, anatomical deformity of the sexual organs, high performance athletes, or incomplete data. A final total of 86 patients were included in the study.

\section{Clinical and nutritional evaluation}

The simplified International Index of Erectile Function-5 questionnaire was applied to identify erectile dysfunction severity (mild, mildmoderate, moderate, and severe). Smoking and alcohol consumption were assessed through the Fagerström test and the Alcohol Use Disorders Identification Test, respectively. Depressive behavior that could indirectly modify erectile function was identified through the Beck Depression Inventory. Metabolic syndrome was diagnosed according to the Adult Panel Treatment III criteria (frequently used in patients with erectile dysfunction).(3) ${ }^{(3)}$ Furthermore, anthropometric measurements (weight, height, neck circumference, and waist circumference) were carried out according to the International Society for the Advancement of Kinanthropometry guidelines. Blood pressure and the following chemical biomarker values were retrieved from the hospital medical records: fasting glucose, glycated hemoglobin, total cholesterol, high-density lipoprotein cholesterol, low-density lipoprotein cholesterol, triglycerides, serum testosterone, and estradiol concentrations.

\section{Statistical analysis}

Normality tests were performed for the continuous variables. Means for independent samples were compared through the Student's t-test. A logistic regression analysis was carried out to identify the risk factors for erectile dysfunction. Beta coefficients with odds ratio (OR) and 95\% confidence intervals ( $95 \% \mathrm{CI}$ ) were determined. A $p<0.05$ value was considered significant. The statistical analysis was performed using the IBM SPSS version 21 Statistics ${ }^{\circledR}$ Software. 


\section{Results}

One hundred and twenty-six patients were initially considered. We excluded 40 candidates and the remaining 86 participants were classified into two groups, according to a positive (70.9\%) or negative metabolic syndrome diagnosis, as depicted in figure 1. Clinical characteristics are compared in table 1. Significant differences in the anthropometric parameters (weight, body mass index, neck circumference, and waist circumference), laboratory values (triglycerides, total cholesterol, glucose, and glycated hemoglobin), clinical characteristics (blood pressure), and the Beck Depression Inventory score were found. However, no differences were detected in the overall International Index of Erectile Function-5 score (13.34 vs 13.76, respectively; $\mathrm{p}=0.707$ ) or the testosterone or estradiol values between the participants that presented with metabolic syndrome and those that did not.

Figure 1. Classification of the study patients based on metabolic syndrome diagnosis, according to the Adult Treatment Panel III.

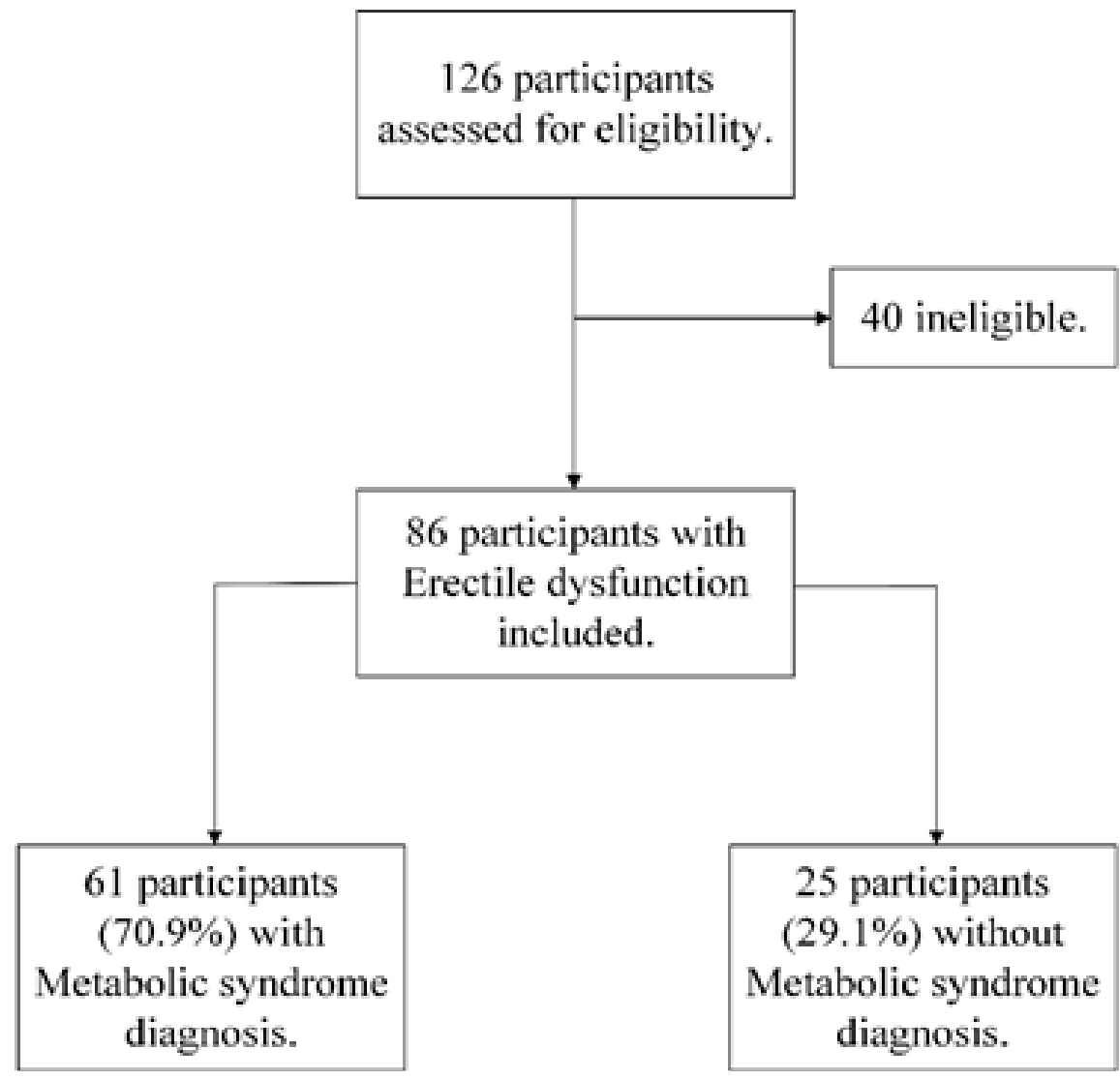


Table 1. Comparison of clinical characteristics in patients presenting with erectile dysfunction, with or without metabolic syndrome. ${ }^{\mathrm{a}}$

\begin{tabular}{|c|c|c|c|}
\hline \multirow[b]{2}{*}{ Characteristic } & \multicolumn{3}{|c|}{ Metabolic Syndrome } \\
\hline & $\begin{array}{c}\text { Yes } \\
(n=61)\end{array}$ & $\begin{array}{c}\text { No } \\
(n=25)\end{array}$ & p-value \\
\hline Age (years) & $52.6 \pm 9.6$ & $50.4 \pm 8.1$ & 0.28 \\
\hline Weight (kg) & $86.7 \pm 13.1$ & $74.3 \pm 12.5$ & $<0.001$ \\
\hline $\operatorname{BMI}\left(\mathrm{kg} / \mathrm{m}^{2}\right)$ & $30.3 \pm 4.1$ & $26.4 \pm 4.1$ & $<0.001$ \\
\hline $\mathrm{WC}(\mathrm{cm})$ & $105.6 \pm 10.4$ & $95.0 \pm 11.1$ & $<0.001$ \\
\hline $\mathrm{NC}(\mathrm{cm})$ & $42.5 \pm 3.1$ & $39.8 \pm 3.1$ & 0.001 \\
\hline TG $(\mathrm{mg} / \mathrm{dL})$ & $190.4 \pm 88.9$ & $118.8 \pm 49.7$ & $<0.001$ \\
\hline HDL-C (mg/dL) & $39.6 \pm 8.8$ & $48.6 \pm 8.2$ & $<0.001$ \\
\hline Glucose $(\mathrm{mg} / \mathrm{dL})$ & $121.2 \pm 46.4$ & $98.5 \pm 43.3$ & 0.036 \\
\hline Hb1Ac (\%) & $6.4 \pm 1.4$ & $5.4 \pm 0.8$ & $<0.001$ \\
\hline Total testosterone (ng/dL) & $422.4 \pm 148.3$ & $448.6 \pm 128.3$ & 0.54 \\
\hline Estradiol $(\mathrm{pg} / \mathrm{mL})$ & $32.4 \pm 22.1$ & $26.8 \pm 14.2$ & 0.36 \\
\hline $\mathrm{SP}(\mathrm{mmHg})$ & $125.5 \pm 12.2$ & $119.5 \pm 10.9$ & 0.032 \\
\hline $\mathrm{DP}(\mathrm{mmHg})$ & $81.8 \pm 8.8$ & $77.4 \pm 7.5$ & 0.024 \\
\hline IIEF-5 (total score) & $13.3 \pm 4.5$ & $13.7 \pm 4.6$ & 0.707 \\
\hline BDI (total score) & $9.8 \pm 7.8$ & $5.5 \pm 4.3$ & 0.002 \\
\hline AUDIT (total score) & $3.2 \pm 4.8$ & $1.8 \pm 2.5$ & 0.091 \\
\hline Fagerström test (total score) & $0.1 \pm 0.7$ & $0 \pm 0$ & 0.055 \\
\hline
\end{tabular}

a According to the Adult Panel Treatment III diagnostic criteria.

International System of Units conversions: $1 \mathrm{mg} / \mathrm{dL}$ of HDL-C= $0.26 \mathrm{mmol} / \mathrm{L} ; 1 \mathrm{mg} / \mathrm{dL}$ of $\mathrm{TG}=$ is $0.01 \mathrm{mmol} / \mathrm{L}$; $1 \mathrm{mg} / \mathrm{dL}$ of glucose $=0.06 \mathrm{mmol} / \mathrm{L}$.

Abbreviations: $\mathrm{BMI}=$ body mass index; $\mathrm{WC}=$ waist circumference; $\mathrm{NC}=$ neck circumference; $\mathrm{TG}=$ triglycerides; HDL-C= high-density lipoprotein cholesterol; HbA1c= glycated hemoglobin; $\mathrm{SP}=$ systolic pressure; $\mathrm{DP}=$ diastolic pressure; IIEF-5= International Index of Erectile Function-5; BDI= Beck's Depression Inventory; AUDIT= Alcohol Use Disorders Identification Test.

Erectile dysfunction severity was classified according to cut-off points into mild, mildmoderate, moderate, and severe, ${ }^{(16)}$ and then further analyzed, considering the presence of metabolic syndrome. More patients in the metabolic syndrome group were affected by severe $(\mathrm{n}=6,66.7 \%)$ and moderate $(\mathrm{n}=13,72.2 \%)$ erectile dysfunction. Erectile dysfunction was more severe in the patients with glycated hemoglobin
$>5.7 \%$, when compared with the patients that had normal glucose metabolism (14.6 vs 12.2, $\mathrm{p}=0.014$, respectively) (Table 2 ). The linear regression analysis (Table 3) identified both glycated hemoglobin $>5.7 \%$ and fasting glucose $>110 \mathrm{mg} / \mathrm{dL}$ as significant risk factors for the development of erectile dysfunction ( $\mathrm{OR}=48.76$, $95 \% \mathrm{CI}=3.6-659.26, \mathrm{p}=0.004 ; \mathrm{OR}=15.62,95 \%$ $\mathrm{CI}=1.12-250, \mathrm{p}=0.04$, respectively). 
Table 2. Metabolic alterations associated with metabolic syndrome and the IIEF-5 score.

\begin{tabular}{lcrrrr}
\hline \multirow{2}{*}{ Metabolic alteration } & \multicolumn{2}{c}{ Yes } & \multicolumn{2}{c}{ No } & \\
& $n$ & mean \pm SD & $n$ & mean \pm SD & $p$-value \\
\hline WC $>102 \mathrm{~cm}$ & 42 & $13.8 \pm 4.4$ & 44 & $13.1 \pm 4.6$ & 0.465 \\
TG $\geq 150 \mathrm{mg} / \mathrm{dL}$ & 45 & $13.4 \pm 3.6$ & 41 & $13.5 \pm 5.4$ & 0.89 \\
$\mathrm{AP} \geq 130 / 85 \mathrm{mmHg}$ & 15 & $14.0 \pm 4.8$ & 71 & $13.3 \pm 4.5$ & 0.638 \\
HDL-C $<40 \mathrm{mg} / \mathrm{dL}$ & 44 & $13.0 \pm 4.3$ & 42 & $13.9 \pm 4.6$ & 0.358 \\
Fasting glucose $>110$ & 26 & $13.5 \pm 4.3$ & 60 & $13.4 \pm 4.6$ & 0.92 \\
mg/dL & & & & & \\
HbA1c $>5.7 \%$ & 41 & $12.2 \pm 4.4$ & 45 & $14.6 \pm 4.3$ & $\mathbf{0 . 0 1 4}$ \\
\hline
\end{tabular}

International System of Units conversions: $1 \mathrm{mg} / \mathrm{dL}$ of $\mathrm{HDL}-\mathrm{C}=0.26 \mathrm{mmol} / \mathrm{L} ; 1 \mathrm{mg} / \mathrm{dL}$ of TG= is $0.01 \mathrm{mmol} / \mathrm{L}$; $1 \mathrm{mg} / \mathrm{dL}$ of glucose $=0.06 \mathrm{mmol} / \mathrm{L}$.

Abbreviations: IIEF-5= International Index of Erectile Function-5; WC= waist circumference; TG= triglycerides; $\mathrm{BP}=$ blood pressure; HDL-C= high-density lipoprotein cholesterol; HbA1c= glycated hemoglobin; $\mathrm{SD}=$ standard deviation.

Table 3. Risk factors associated with erectile dysfunction. ${ }^{\mathrm{a}}$

\begin{tabular}{lrrr}
\hline \multicolumn{1}{c}{ Risk factor } & Beta Coefficient & \multicolumn{1}{c}{ OR $(95 \%$ CI } & \multicolumn{1}{c}{$p$-value } \\
\hline Metabolic syndrome ${ }^{\mathrm{b}}$ & -0.087 & $0.42(0.01-10.58)$ & 0.594 \\
Fagerström test & -0.034 & $0.55(0.01-26.54)$ & 0.761 \\
AUDIT & 0.099 & $11.19(0.04-2900.38)$ & 0.389 \\
BDI & 0.145 & $4.06(0.38-43.22)$ & 0.241 \\
Hypertension & 0.021 & $1.27(0.07-21.85)$ & 0.863 \\
Hb1Ac $>5.7 \%$ & 0.432 & $48.76(3.6-659.26)$ & $\mathbf{0 . 0 0 4}$ \\
Glucose $>110 \mathrm{mg} / \mathrm{dL}$ & -0.28 & $15.62(1.12-250)$ & $\mathbf{0 . 0 4}$ \\
HDL-C $<40 \mathrm{mg} / \mathrm{dL}$ & 0.1 & $2.46(0.22-26.84)$ & 0.455 \\
Triglycerides $\geq 150 \mathrm{mg} / \mathrm{dL}$ & 0.04 & $1.43(0.14-14.01)$ & 0.751 \\
WC $>102 \mathrm{~cm}$ & 0.08 & $2.06(0.1-39)$ & 0.626 \\
BMI $\geq 30 \mathrm{~kg} / \mathrm{m}^{2}$ & -0.409 & $0.02(0.0002-1.93)$ & 0.094 \\
$25 \leq$ BMI $<30 \mathrm{~kg} / \mathrm{m}^{2}$ & -0.106 & $0.38(0.01-10.37)$ & 0.566 \\
Testosterone $<350 \mathrm{ng} / \mathrm{dL}$ & -0.268 & $1.3(0.05-11.66)$ & 0.846 \\
\hline
\end{tabular}

${ }^{a}$ Linear regression analysis.

${ }^{\mathrm{b}}$ Diagnosis according to the Adult Panel Treatment III criteria.

International System of Units conversions: $1 \mathrm{mg} / \mathrm{dL}$ of $\mathrm{HDL}-\mathrm{C}=0.26 \mathrm{mmol} / \mathrm{L} ; 1 \mathrm{mg} / \mathrm{dL}$ of TG= is $0.01 \mathrm{mmol} / \mathrm{L}$; $1 \mathrm{mg} / \mathrm{dL}$ of glucose $=0.06 \mathrm{mmol} / \mathrm{L} ; 1 \mathrm{mg}$ of testosterone $=0.03 \mathrm{nmol} / \mathrm{L}$.

Abbreviations: Metabolic syndrome = Metabolic Syndrome, AUDIT=Alcohol Use Disorders Identification Test; $\mathrm{BDI}=$ Beck's Depression Inventory; HbA1c= glycated hemoglobin; HDL-C= high-density lipoprotein cholesterol; $\mathrm{WC}=$ waist circumference; $\mathrm{BMI}=$ body mass index, $\mathrm{OR}=$ Odds ratio, $95 \% \mathrm{CI}=95 \%$ confidence interval. 


\section{Hiperglucemia: el componente del síndrome metabólico que agrava la disfunción... Espinosa -Marrón A., et al.}

\section{Discussion}

Our study provides relevant evidence suggesting that erectile dysfunction pathogenesis is exacerbated by metabolic syndrome in a Mexican population, especially by uncontrolled glycemia. Poor eating habits have been reported in different Mexican surveys. The results of the latest national health survey Encuesta Nacional de Salud y Nutrición (ensanut), ${ }^{(17)}$ showed that the combined prevalence of overweight/ obesity reached $72.5 \%$ in adults $(<20$ years of age). Overweight/obese patients usually present with glycemic dysregulation secondary to elevated concentrations of serum-free fatty acids (induced by apoptosis of the pancreatic $\beta$-cells) and leptin and TNF- $\alpha$ (both of which restrict insulin secretion), subsequently reducing insulin secretory capacity. ${ }^{(18)}$

Méndez-Hernández et al., ${ }^{(19)}$ reported that individuals classified as having undesirable eating habits have an $8.8(95 \% \mathrm{CI}=3.1-25)$ and 11.1 (95\% CI $=3.4-36.1)$ higher risk of developing metabolic syndrome (considering the NCEP-ATP III and International Diabetes Federation criteria, respectively) and an 11.2 (95\% $\mathrm{CI}=3.9-31.5$ ) higher probability of presenting with insulin resistance, when compared with individuals that have healthier eating habits. Consequently, subjects with undesirable eating habits are also predisposed to develop erectile dysfunction, which could explain the large prevalence of erectile dysfunction found in our Mexican patients. ${ }^{(4,5)}$

Furthermore, our results agree with those published by Chao et al., who found a significant association between anthropometric parameters, such as central obesity (for the Asian population, waist circumference $\geq 90 \mathrm{~cm}$ ), and erectile dysfunction $(\mathrm{p}=0.007){ }^{(20)}$ Other stud- ies on different populations have shown that particular relationship. ${ }^{(21)}$ However, in contrast to our results, there is evidence showing a significant difference in the International Index of Erectile Function- 5 score between men that do not present with metabolic syndrome and those that present with the syndrome (21.76 \pm 3.59 vs $18.26 \pm 5.08$ respectively, $\mathrm{p}<0.001$ ), possibly indicating that erectile dysfunction prevalence increases when a patient has more components of metabolic syndrome. ${ }^{(20)}$

Regarding arterial hypertension, the authors of a multicenter cross-sectional study on 512 hypertensive patients that answered the International Index of Erectile Function-5 questionnaire, reported a prevalence of erectile dysfunction of $46.5 \%$, like that found in our study. ${ }^{(22)}$ However, evidence on the association between depression, metabolic syndrome, and erectile dysfunction described in the medical literature is not conclusive. In a prospective study on patients with metabolic syndrome $(n=5,232)$, only central obesity, high triglyceride concentration, and low highdensity lipoprotein cholesterol concentration predicted depression symptoms. ${ }^{(23)}$ Our results demonstrated a trend toward the development of depression in patients with metabolic syndrome diagnosed through the Beck Depression Inventory.

Our biochemical results matched those reported in a systematic review and meta-analysis by Besiroglu et al., ${ }^{(21)}$ in which there was a positive association between erectile dysfunction and hyperlipidemia. In a prospective study on a cohort of men, hypercholesterolemia was found to be a long-term erectile dysfunction predictor. (24) Moreover, data from experimental models have demonstrated that the atherosclerotic process caused by hypercholesterolemia affects the 
corpus cavernosum and that the reduction of serum cholesterol normalizes cavernosal relaxation, suggesting that the corpus cavernosum smooth muscle dysfunction caused by hypercholesterolemia is reversible. ${ }^{(25)}$ In that context, a prospective clinical trial evaluated the impact of cardiovascular risk factors on erectile function. Those authors concluded that age, body mass index, total cholesterol, and triglyceride concentrations were significantly associated with erectile dysfunction. ${ }^{(12)}$

With respect to the lack of glycemic control, Maseroli et al., reported a higher prevalence of hyperglycemia (fasting glucose $>100$ $\mathrm{mg} / \mathrm{dL}_{\text {) }}$ in patients with sexual dysfunction than in patients not presenting with the disor$\operatorname{der}(44.5$ vs $33.3 \%, \mathrm{p}<0.05) .{ }^{(26)}$

Specifically, those authors observed a direct relation between a higher serum glucose concentration and the development of erectile dysfunction. Furthermore, Pohjantähti-Maaroos et al., analyzed 57 subjects with metabolic syndrome, comparing them with 48 physically active individuals, and found there were more cases of erectile dysfunction in the metabolic syndrome group. In addition, the patients with metabolic syndrome and erectile dysfunction had a higher mean serum glucose concentration than the patients with metabolic syndrome that did not present with erectile dysfunction (6.99 $\pm 2 \mathrm{mmol} / \mathrm{L}$ vs $6.54 \pm 1 \mathrm{mmol} / \mathrm{L}$, respectively) $(\mathrm{p}<0.001) .{ }^{(27)} \mathrm{Xu}$ et al., recruited patients with type 2 diabetes mellitus and evaluated erectile dysfunction (through the International Index of Erectile Function-5) and concluded that the risk for erectile dysfunction was greater in patients with poor glycemic control. ${ }^{(28)}$ An observational study on a Mexican population, in which glycated hemoglobin concentrations were associated with the overall score on the
International Index of Erectile Function-5 questionnaire, produced an odds ratio of 6.92 . In that set of patients, the prevalence of erectile dysfunction was $72 \%$ and the lack of glycemic control was observed in $80.9 \%$ of the patients. (14) Similar results were found in our study, concluding that glycated hemoglobin $>5.7 \%$ and/ or fasting glucose $>110 \mathrm{mg} / \mathrm{dL}$ may directly influence the severity of erectile dysfunction in patients with metabolic syndrome.

Although it is well known that erectile dysfunction is potentially caused by testosterone deficiency, hypogonadism, and age, and in addition, the long-term benefit of testosterone replacement has been addressed, ${ }^{(12,29)}$ our results did not show a relation between testosterone concentrations below $346 \mathrm{ng} / \mathrm{dL}(12 \mathrm{nmol} / \mathrm{L})$ and the development of erectile dysfunction in patients with metabolic syndrome, nor did they corroborate an etiological association between patient age and the development of erectile dysfunction. Nonetheless, hyperglycemia promotes alterations in the concentrations of nitric oxide, cyclic guanosine monophosphate (cGMP), and free radicals, as well as in endothelin B biosynthesis, all possible direct causes of erectile dysfunction. ${ }^{(14)}$ Consequently, the etiology of erectile dysfunction is closely related to different factors specifically associated with glycemic dysregulation, in that particular group of patients. However, both adipose tissue-derived hormones (which are also associated with insulin resistance) and vascular disease compromise blood flow to the penis and are presumably caused by nitric oxide synthase inhibition. Therefore, to have an overall pathophysiological understanding of erectile dysfunction, adipokines should be considered in patients that present with erectile dysfunction and metabolic syndrome. ${ }^{(30)}$ 
Our study provides evidence on metabolic syndrome as a risk factor for the development and progression of erectile dysfunction that can be extrapolated to other Latin American populations. In addition to the fact that our findings partially coincide with the existing evidence, ${ }^{(9,15)}$ we reinforce the hypothesis that hyperglycemia promotes the development of erectile dysfunction. Standards for the prevention and treatment of erectile function that focus on metabolic and glycemic control are fundamental for improving the condition. However, limitations of our study were its observational and cross-sectional design and the size of the sample, possibly reducing the statistical reliability of our analysis. In the context of small sample size, employing logistic regression as an analytical tool could overestimate the effect, yielding large confidence intervals and possibly biased odds ratios. ${ }^{(31)}$ Nevertheless, our adequate and well-designed sampling strategy rectified the performance of the estimates. That probable source of bias in a single study might not be relevant in the interpretation of the results, given that said misrepresentation usually occurs when small studies with systematically overestimated effect sizes are pooled together (i.e., meta-analysis). ${ }^{(31)}$ Thus, those limitations are not major concerns regarding the clinical interpretation of our exploratory design, which may be helpful in the development of etiological hypotheses for future larger longitudinal studies.

\section{Conclusions}

Metabolic syndrome components were directly associated with the severity of erectile dysfunction, particularly hyperglycemia, manifested by glycated hemoglobin $>5.7 \%$ and fasting glucose
$>110 \mathrm{mg} / \mathrm{dL}$. Those results agree with other previously published findings. However, our study provides a specific description of the influence of each metabolic syndrome component on the severity of erectile dysfunction. Therefore, it is necessary to produce population-based guidelines and recommendations to develop a multidisciplinary treatment for erectile dysfunction that addresses the importance of metabolic syndrome prevention by promoting an adequate lifestyle for Latin American men. The present study contributes to that goal by strongly suggesting the inclusion of basal glucose and/or HB1AC as complementary biochemical screening for erectile dysfunction.

\section{References}

1. Grundy SM. Metabolic syndrome update. Trends Cardiovasc Med. 2016;26(4):364-73. doi: 10.1016/j.tcm.2015.10.004

2. National Cholesterol Education Program. Report of the Expert Panel on Population Strategies for Blood Cholesterol Reduction: executive summary. National Heart, Lung and Blood Institute, National Institutes of Health. Arch Intern Med. 1991;151(6):1071-84. doi: 10.1001/archinte.151.6.1071

3. Gorgel SN, Gorgel A, Sefik E. Sexual Function in Male Patients with Metabolic Syndrome and Effective Parameters on Erectile Dysfunction. Int Braz J Urol. 2014;40(1):56-61. doi: 10.1590/ S1677-5538.IBJU.2014.01.08

4. Rojas R, Aguilar-Salinas CA, Jiménez-Corona A, Shamah-Levy T, Rauda J, Avila-Burgos L, et al. Metabolic syndrome in Mexican adults: results from the National Health and Nutrition Survey 2006. Salud Publica Mex. 2010;52 Suppl 1: S1118. doi: 10.1590/s0036-36342010000700004 
5. Salas R, Bibiloni M del M, Ramos E, Villarreal JZ, Pons A, Tur JA, et al. Metabolic syndrome prevalence among Northern Mexican adult population. PLoS ONE. 2014;9(8): e105581. doi: 10.1371/journal.pone.0105581

6. Wentzell E, Salmeron J. Prevalence of Erectile Dysfunction and Its Treatment in a Mexican Population: Distinguishing between Erectile Function Change and Dysfunction. Journal of Men s Health. 2009; 6:56-62. doi: 10.1016/j. jomh.2008.09.009

7. Yafi FA, Jenkins L, Albersen M, Corona G, Isidori AM, Goldfarb S, et al. Erectile dysfunction. Nat Rev Dis Primers. 2016; 2:16003. doi: 10.1038/nrdp.2016.3

8. Borges R, Temido $\mathbf{P}$, Sousa $\mathbf{L}$, Azinhais $\mathbf{P}$, Conceição P, Pereira B, et al. Metabolic Syndrome and Sexual (Dys)function. The Journal of Sexual Medicine. 2009;6(11):295875. doi: 10.1111/j.1743-6109.2009.01412.x

9. Bal K, Öder M, Şahin AS, Karataş CT, Demir Ö, Can E, et al. Prevalence of Metabolic Syndrome and Its Association with Erectile Dysfunction Among Urologic Patients: Metabolic Backgrounds of Erectile Dysfunction. Urology. 2007;69(2):356-60. doi: 10.1016/j. urology.2006.09.057

10. Ning L, Yang L. Hypertension might be a risk factor for erectile dysfunction: a metaanalysis. Andrologia. 2017;49(4). doi: 10.1111/ and.12644

11. Kouidrat Y, Pizzol D, Cosco T, Thompson T, Carnaghi M, Bertoldo A, et al. High prevalence of erectile dysfunction in diabetes: a systematic review and meta-analysis of 145 studies. Diabet Med. 2017;34(9):1185-92. doi: 10.1111/ dme.13403

12. Gandaglia G, Briganti A, Jackson G, Kloner RA, Montorsi F, Montorsi P, et al. A Systematic Review of the Association Between Erectile
Dysfunction and Cardiovascular Disease. European Urology. 2014;65(5):968-78. doi: 10.1016/j.eururo.2013.08.023

13. Traish AM, Feeley RJ, Guay A. Mechanisms of obesity and related pathologies: Androgen deficiency and endothelial dysfunction may be the link between obesity and erectile dysfunction. FEBS J. 2009;276(20):5755-67. doi: 10.1111/j.1742-4658.2009.07305.x

14. Figueroa-García J, Pérez-Patraca A de J. Association of glycemic control and erectile dysfunction in diabetic patients. Rev Mex Urol. 2017;77(1):5-11.

15. Chen K, Mi H, Gao Y, Tan A, Lu Z, Wu C, et al. Metabolic Syndrome: A Potential and Independent Risk Factor for Erectile Dysfunction in the Chinese Male Population. Urology. 2012;80(6):1287-92. doi: 10.1016/j. urology.2012.08.028

16. Rosen RC, Cappelleri JC, Smith MD, Lipsky J, Peña BM. Development and evaluation of an abridged, 5-item version of the International Index of Erectile Function (IIEF-5) as a diagnostic tool for erectile dysfunction. Int J Impot Res. 1999;11(6):319-26. doi: 10.1038/ sj.ijir.3900472

17. Gutiérrez JP, Rivera-Dommarco J, ShamahLevy T, Villalpando-Hernández S, Franco A, Cuevas-Nasu L, et al. Encuesta Nacional de Salud y Nutrición 2012. Resultados Nacionales. Cuernavaca: Instituto Nacional de Salud Pública; 2012.196p. Availablefrom:https://ensanut.insp. $\mathrm{mx} /$ encuestas/ensanut2012/doctos/informes/ ENSANUT2012ResultadosNacionales.pdf

18. Hajer GR, van Haeften TW, Visseren FLJ. Adipose tissue dysfunction in obesity, diabetes, and vascular diseases. Eur Heart J. 2008;29(24):2959-71. doi: 10.1093/eurheartj/ ehn387 
19. Méndez-Hernández P, Dosamantes-Carrasco LD, Siani C, Pierlot R, Martínez-Gómez M, Rivera-Paredez B, et al. Mealtime habits and risk of developing the metabolic syndrome or insulin resistance among Mexican adults. $\mathrm{Br}$ J Nutr. 2016;116(10):1824-33. doi: 10.1017/ S0007114516003329

20. Chao J-K, Kuo W-H, Chiang H-S, Hwang TI-S, Chao I-C, Chiang S-K. Association of metabolic syndrome, atherosclerosis risk factors, sex hormones in ED in aboriginal Taiwanese. Int J Impot Res. 2012;24(4):141-6. doi: 10.1038/ ijir.2012.5

21. Besiroglu H, Otunctemur A, Ozbek E. The Relationship Between Metabolic Syndrome, Its Components, and Erectile Dysfunction: A Systematic Review and a Meta-Analysis of Observational Studies. J Sex Med. 2015 Jun 1;12(6):1309-18. doi: 10.1111/jsm.12885

22. Cuéllar de León AJ, Ruiz García V, Campos González JC, Pérez Hoyos S, Brotons Multóe F. Prevalencia de disfunción eréctil en pacientes con hipertensión arterial. Med Clin (Barc). 2002;119(14):521-6.

23. Akbaraly TN, Kivimäki M, Brunner EJ, Chandola T, Marmot MG, Singh-Manoux A, et al. Association Between Metabolic Syndrome and Depressive Symptoms in Middle-Aged Adults: Results from the Whitehall II study. Diabetes Care. 2009 Mar 1;32(3):499-504. doi: $10.2337 / \mathrm{dc} 08-1358$

24. Barrett-Connor E. Heart Disease Risk Factors Predict Erectile Dysfunction 25 Years Later (The Rancho Bernardo Study). American Journal of Cardiology. 2005;96(12):3-7. doi: 10.1016/j.amjcard.2005.07.012

25. Kim Jay H., Klyachkin Michael L., Svendsen Einar, Davies Mark G., Hagen Per-Otto, Carson Culley C. Experimental Hypercholesterolemia in Rabbits Induces Cavernosal Atherosclerosis with Endothelial and Smooth Muscle Cell Dysfunction. J Urol. 1994;151(1):198-205. doi: 10.1016/S0022-5347(17)34916-9

26. Maseroli E, Corona G, Rastrelli G, Lotti F, Cipriani S, Forti G, et al. Prevalence of Endocrine and Metabolic Disorders in Subjects with Erectile Dysfunction: A Comparative Study. The Journal of Sexual Medicine. 2015;12(4):956-65. doi: $10.1111 /$ jsm.12832

27. Pohjantähti-Maaroos $\mathbf{H}$, Palomäki A, Hartikainen J. Erectile dysfunction, physical activity and metabolic syndrome: differences in markers of atherosclerosis. BMC Cardiovascular Disorders. 2011;11(1):36. doi: 10.1186/14712261-11-36

28. Xu Y, Zhang Y, Yang Y, Liu L, Chen Y, Liu X. Prevalence and correlates of erectile dysfunction in type 2 diabetic men: a population-based crosssectional study in Chinese men. International Journal of Impotence Research. 2019;31(1):914. doi: 10.1038/s41443-018-0060-4

29. Pagano MJ, Fazio AD, Levy A, RoyChoudhury A, Stahl PJ. Age, Body Mass Index, and Frequency of Sexual Activity are Independent Predictors of Testosterone Deficiency in Men with Erectile Dysfunction. Urology. 2016; 90:112-8. doi: 10.1016/j.urology.2015.12.030

30. Dozio E, Barassi A, Dogliotti G, Malavazos AE, Colpi GM, D'Eril GVM, et al. Adipokines, Hormonal Parameters, and Cardiovascular Risk Factors: Similarities and Differences Between Patients with Erectile Dysfunction of Arteriogenic and Nonarteriogenic Origin. J Sex Med. 2012;9(9):2370-7. doi: 10.1111/j.17436109.2012.02781.x

31. Nemes S, Jonasson JM, Genell A, Steineck G. Bias in odds ratios by logistic regression modelling and sample size. BMC Med Res Methodol. 2009;9(1):56. doi: 10.1186/14712288-9-56 